\title{
DETECTION OF INTRATHECAL IGM, IGG AND IGA IN A CUBAN WEST NILE VIRUS CONFIRMED CASE
}

\author{
Maritza Pupo-Antúnez', Alberto Juan Dorta-Contreras², Yaimee Vazquez', \\ Marlen González-Hernández², Elena Noris-García², Bárbara Padilla-Docal ${ }^{2}$, Raisa Bu-Coifiu-Fanego ${ }^{2}$
}

West Nile virus (WNV) is a flavivirus grouped in Japanese encephalitis virus serogroup due to serological antigenic characteristics. WNV is transmitted to humans through the bite of infected mosquitoes which acquire the virus after feeding on vertebrate amplifying hosts, mainly birds. WNV is endemic in great parts of Africa and it has been reported in Europe, the Middle East, Africa, India, parts of Asia, Australia (Kunjin virus, a subtype of WNV). In 1999, the virus was detected in the Western Hemisphere for the first time in New York City. After that, WNV has spread considerably throughout Latin America and the Caribbean ${ }^{1,2}$.

Approximately $80 \%$ of WNV-infected patients are asymptomatic, 20\% develop West Nile fever (WNF), and less than $1 \%$ develops West Nile neuroinvasive disease (WNND) $)^{3}$.

WNV central nervous system (CNS) disease occurs frequently in immunocompromised persons and the elderly'. The specific mechanism by which WNV enters the CNS is unknown, but it suggested from experimental WNV infection results high levels of inflammatory cytokines including tumour necrosis factor which can alter blood-brain barrier (BBB) permeability ${ }^{4}$.

\section{CASE}

We report the detection of intrathecal IgM, IgA and IgG synthesis in Cuban West Nile confirmed case to assess the possible dysfunction of blood cerebrospinal fluid (CSF) barrier using Reiber's formula.

The albumin and IgG concentrations were determined in serum and CSF by immunodiffusion method by NOR and LC Partigen immunoplates (Dade Behring, Marburg, Germany) in a Cuban confirmed case during WNV Surveillance in Cuba 2003. The albumin quotient (Alb $\mathrm{Q}=\mathrm{CSF}$ albumin/serum albumin) was used to evaluate the integrity of the blood-CSF barrier using previously described protocols ${ }^{5,6}$.

The presence of intrathecal synthesis of IgM, IgG and IgA was demostrated by using Reiber's graph or reibergram ${ }^{5-7}$.

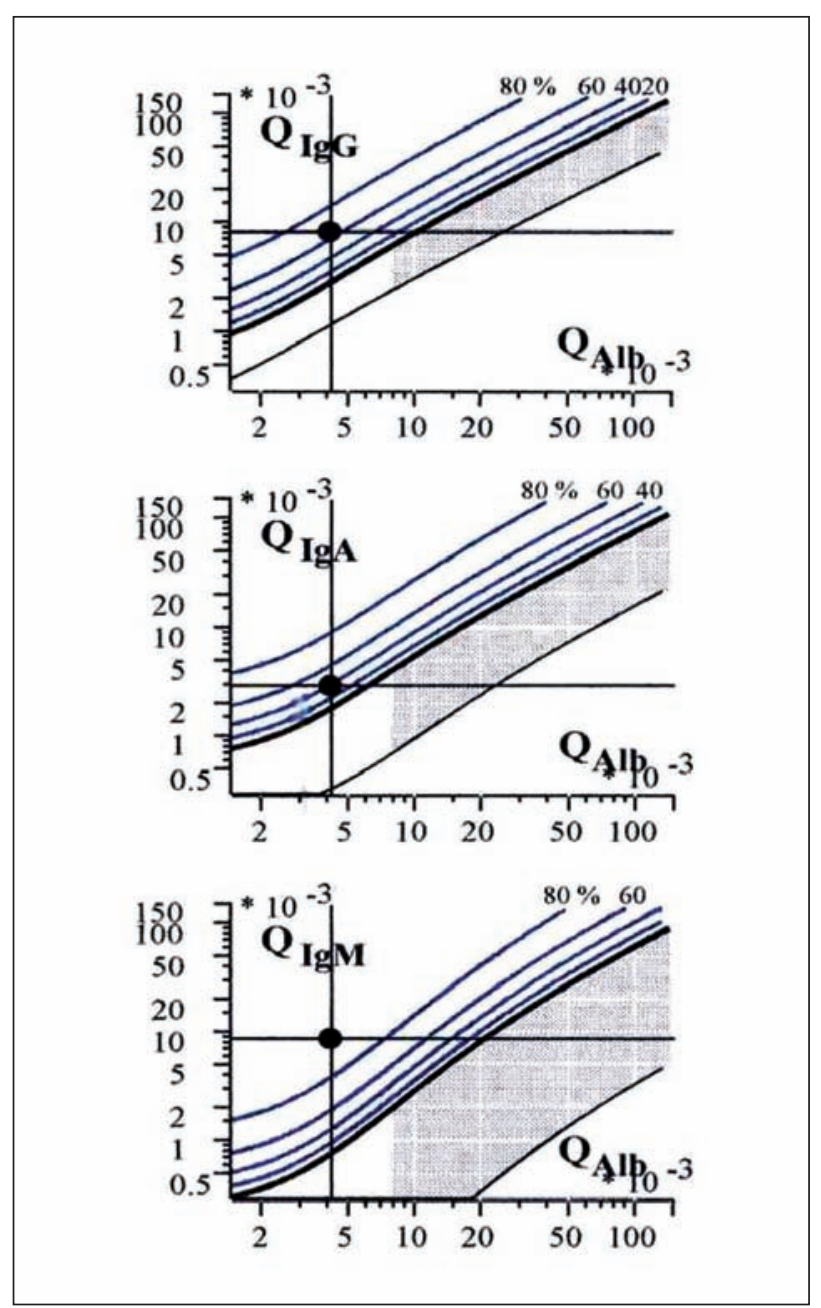

Figure. Reibergram from the WNV confirmed case. CSF/serum quotient diagrams for $\lg G \lg A$, and $\lg M$ (Reibergrams). The upper hyperbolic curves (thick lines) represent the discrimination lines between brain-derived and blood-derived immunoglobulin fractions. Values above these upper discrimination lines represent intrathecal $\lg G$, IgA, or IgM synthesis. The blue lines indicate the extent of intrathecal synthesis as intrathecal fractions (IgGIF, IgAIF,or IgMIF) with $20 \%, 40 \%, 60 \%$, and $80 \%$ of the measured total immunoglobulin concentration in CSF, with reference to the discrimination line as $0 \%$ intrathecal synthesis.

\section{DETECCIÓN INTRATECAL DE IGM, IGG E IGA EN UN CASO CONFIRMADO DE INFECCIÓN POR VIRUS DEL NILO OCCIDENTAL EN CUBA}

'PhD, Tropical Medicine Institute "Pedro Kouri”; ${ }^{2}$ Laboratorio Central de Líquido Cefalorraquídeo (LABCEL).Facultad de Ciencias Médicas "Dr. Miguel Enríquez" Habana, Cuba.

Received 18 September 2007, received in final form 6 June 2008. Accepted 11 June 2008.

Dra. Maritza Pupo-Antúnez - Novia del Mediodía Km 6 1⁄2 - La Lisa, Habana, Cuba. E-mail: mpupo@ipk.sld.cu 
Table. WNV Antibody index.

\begin{tabular}{ccccc}
\hline Qspecific $^{a}$ & QAlbumin $^{b}$ & QlgG $^{c}$ & QLim $^{\text {d }}$ & WNV Antibody Index $^{\mathrm{e}}$ \\
\hline $35.6 \times 10^{-3}$ & $4.81 \times 10^{-3}$ & $8 \times 10^{-3}$ & $2.74 \times 10^{-3}$ & 13.02 \\
\hline
\end{tabular}

${ }^{\mathrm{a}} \mathrm{CSF}$ WNV specific antibodies/Serum WNV specific antibodies quotient; ${ }^{\mathrm{b}} \mathrm{CSF}$ Albumin/Serum Albumin quotient. Qalb is a marker of blood-CSF barrier; ${ }^{\mathrm{C} C S F} \operatorname{lgG} / \mathrm{CSF}$ serum quotient; ${ }^{\mathrm{d}} \mathrm{Q} \lg \mathrm{Lim}_{\mathrm{Lim}}=0,93 \sqrt{ }\left[(\mathrm{Q} \text { alb })^{2}+6 \times 10^{-6}\right]-1,7 \times 10^{-3} ; \mathrm{e} \mathrm{IA}=\mathrm{Q}$ espec/QIgG.

WNV specific antibodies were calculated by using antibody index according to previous formulae ${ }^{7,8}$.

The patient was identified as part of WNV Cuban surveillance in 2003 and exhibited febrile illness, intense and frontal cephaleas, muscle weakness, encephalitis, myalgias, arthralgias and was hospitalized. This person had different jobs that required spending large amounts of time outdoors. This patient was localized in a community in central part of the Island ${ }^{9}$. The ethical approval of the study was granted according to the principles of the Declaration of Helsinki.

Both acute-phase and convalescent phase serum specimens from this patient was positive for flavivirus antibody by IgM and IgG ELISAs. CSF was also positive for IgM by WNV ELISA?

The patient exhibited three class patterns of immunoglobulins intrathecal synthesis at the time of the lumbar puncture. It is important to point out that it was not the first diagnostic lumbar puncture performed on this patient. The sample was taken during the acute phase of the central nervous system infection.

At the Figure IgA, IgM and IgG intrathecal synthesis was observed by Reiber's graph or reibergramas. Notice that the plotted point are over the darkest hyperbolic line that indicates the limit between brain-derived fraction from the blood-derived fraction.

Table shows in details the figures of Qalb, QIgQ and Q lim and the Antibody index for WNV

\section{DISCUSSION}

WNV disease in the central nervous system occurs frequently in elderly and in immunocompromised individuals. The specific mechanism by which WNV enters the CNS is unknown, but experimental WNV infection results in elevated levels of inflammatory cytokines including tumor necrosis factor- $\alpha$ which can alter blood-brain barrier permeability ${ }^{3,4}$.

Intrathecal Igs synthesis during a variety of CNS diseases, principally inflammatory diseases is originated by perivascular infiltrations from B lymphocytes locally matured which can be associated to CNS diseases. The relation among intrathecal fractions of one or more Ig classes or the predominance of one of them, have create a typical intrathecal synthesis pattern of some neurological diseases produced by bacteria, viruses and parasites among others ${ }^{8,10}$.

Detection of WNV IgM in CSF is one of most impor- tant criteria and is a diagnostic of neuroinvasive disease. In sera WNV IgM antibody persists for at least 6 months, and sometimes for 12-16 months in previously infected patients, however IgM antibody in CSF is detectable up to 7 months after illness ${ }^{11}$. Other authors report the value of IgM and also IgA as indicator of CNS involvement following WNV infection ${ }^{12}$.

The presence of intrathecal synthesis of three immunoglobulin classes is a clear evidence of an inflammatory process at CNS.

In our result is very interesting that the intrathecal fractions are present in decreasing order $\lg M>|g G>| g A$.

There is a fact which clearly reveals that infectious process of CNS is due to WNV and it is that antibody index reaches a value greater than 1.5. That means that the causal agent of this infection is WNV.

Detection of intrathecal WNV IgM from CSF and sera has been detected by ELISA test. In some cases have been shown an unexpected onset of the intrathecal specific humoral immune response before serum immunoglobulins synthesis was recorded ${ }^{13}$.

Reiber's hyperbolic formula and Öhman's extended immunoglobulin indices are based on the demonstration of non-linear relationships between the Qalb and CSFserum concentration quotients for IgG, IgA and IgM to determine whether there is a disruption of the blood-CSF barrier and intrathecal syntesis of immunoglobulins $s^{5,10,14-16}$.

However Reiber's hyperbolic formula has been just used in a veterinarian studies which suggested a normal BBB integrity and increased intrathecal production of antibodies $^{17,18}$.

Our study is the first report of anti-WNV IgA and IgG antibodies intrathecal synthesis in a human being.

\section{REFERENCES}

1. Hayes EB, Gubler DJ. West Nile virus: epidemiology and clinical features of an emerging epidemic in the United States. Annu Rev Med 2006;57:181-194.

2. Briese T, Bernard KA. West Nile virus, and old virus learning new tricks? J Neurovirol 2005;11:469-475.

3. Davis LE, DeBiasi R, Goade DE, et al. West Nile virus neuroinvasive disease. Ann Neurol 2006;60:286-300.

4. Wang T, Town T, Alexopoulou L, et al. Toll-like receptor mediates West Nile virus entry into the brain causing lethal encephalitis. Nat Med 2004;10:1366-1372. 
5. Reiber H, Peter JB. Cerebrospinal fluid analysis: disease-related data patterns and evaluation programs. J Neurol Sci 2001;184:101-122.

6. Reiber H, Felgenhauer K. Protein transfer at the blood cerebrospinal fluid barrier and the quantitation of the humoral immune response within the central nervous system. Clin Chim Acta 1987;163:319-328.

7. Dorta-Contreras AJ, Noris-Garcia E, Escobar-Perez X, Padilla-Docal B. IgG1, IgG2 and IgE intrathecal synthesis in Angiostrongylus cantonensis meningoencephalitis. J Neurol Sci 2005;238:65-70.

8. Dorta-Contreras AJ. Respuesta poliespecífica en el sistema nervioso central: uso del índice de anticuerpo. Rev Neurol 2000;31:1070-1073.

9. Pupo M. West Nile virus infection in humans and horses, Cuba. Emerg Infect Dis 2006;12:1022-1024

10. Lawrence R. The role of lumbar puncture as a diagnostic tool in 2005 Crit Care Resusc 2005;7:213-220.

11. DeBiasi RL, Tyler KL. West Nile virus meningoencephalitis. Nature Clin Practice Neurol 2006;2:264-275.

12. Nixon ML, Prince HE. West Nile virus immunoglobulin A (WNV IgA) detection in cerebrospinal fluid in relation to WNV IgG and IgM reactivity. J Clin Virol 2006;37:174-178.
13. Cernescu C, Ruta SM, Tardei G, et al. A high number of severe neurologic clinical forms during an epidemic of West Nile virus infection. Rom J Virol 1997;48:13-25.

14. Reiber H. Flow rate of cerebrospinal fluid (CSF): a concept common to normal blood-CSF barrier function and to dysfunction in neurological diseases. J Neurol Sci 1994;122:189-203.

15. Ohman S, Ernerudh J, Forsberg P, von Schenck H, Vrethem M. Improved formulae for the judgement of intrathecally produced $\operatorname{IgA}$ and IgM in the presence of blood CSF barrier damage. Ann Clin Biochem 1993;30:454-462.

16. Ohman S, Forsberg P, Nelson N, Vrethem M. An improved formula for the judgement of intrathecally produced IgG in the presence of blood brain barrier damage. Clin Chim Acta 1989;181:265-272.

17. Deisenhammer F, Bartosb A, Egga R, et al. Guidelines on routine cerebrospinal fluid analysis: report from an EFNS task force. Eur J Neurol 2006;13:913-922.

18. Porter MB. Immunoglobulin M-capture enzyme-linked immunosorbent assay testing of cerebrospinal fluid and serum from horses exposed to West Nile virus by vaccination or natural infection. J Vet Intern Med 2004; 18:866-870. 